\title{
Infantile Cortical Hyperostosis (ICH) Secondary to Prostaglandin E1 Infusion in a Newborn with Complex Cyanotic Heart Disease: A Case Report
}

\author{
Kishan Rao Subramaniam*, Rajandra Kumar Karupiah, Ed Simor Khan and Zamzuri Zakaria \\ Department of Orthopedics,International Islamic University of Malaysia, Malaysia \\ *Corresponding author: Kishan Rao Subramaniam, Department of Orthopedics,International Islamic University of Malaysia, Malaysia
}

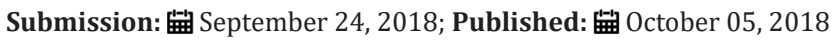

\begin{abstract}
Infantile cortical hyperostosis (ICH), also known as Caffey's disease, is a benign self-limiting condition affecting young infants. The initial symptom of the classical ICH is usually irritability, fever and soft tissue swelling affecting one or more bones. Diagnosis is usually delayed because its clinical presentation mimics many other clinical conditions such as osteomyelitis, scurvy, hypervitaminosis A, child abuse, bone tumor or even fracture. There are no laboratory tests to confirm the diagnosis. There are two types of ICH been described; the classical mild infantile form and the more severe prenatal form. Most of the cases of ICH are sporadic, but autosomal dominant and recessive patterns have been reported as well. It is linked with missense mutation in COL1A1, the gene encoding the $\alpha 1$ chain of type I collagen and has raised some doubts whether it is a type of collagen disorder, like osteogenesis imperfect. In this case, the newborn developed ICH due to prolonged infusion with prostaglandin E1 which was given in view of congenital cyanotic heart disease. Prostaglandin E1 infusion is used for maintaining the patency of ductus arteriosus in ductus dependent congenital heart defects in neonates and is usually administered before corrective heart surgery. ICH is mostly self-limiting and resolves within $12-24$ months and usually does not require any treatment. Anti-inflammatory drugs such as NSAIDS (indomethacin and naproxen) and steroids has been used in symptomatic cases with success. The outcome is generally good with symptoms resolution usually before the age of one year. Relapses are uncommon.
\end{abstract}

Keywords: Infantile cortical hyperostosis; Caffey's disease; Prostaglandin E1

\section{Introduction}

Infantile cortical hyperostosis (ICH) is a benign self-limiting condition affecting young infants. The symptoms are irritability, fever and hyperostosis of bones. ICH usually presents within 6 months of life but can also present at birth. The diagnosis of ICH is often difficult as there are many clinical conditions that have similar presentations such as acute osteomyelitis, hypervitaminosis A, non-accidental injuries, bone malignancies and fractures. In our case, the new born developed ICH due to prolonged infusion with prostaglandin E1 which was given in view of congenital cyanotic heart disease. There are no diagnostic laboratory tests for ICH. X ray features show layers of periosteal new bone formation, with cortical thickening sparing the metaphysis and epiphysis. In view ICH is a very rare disease, other conditions need to be excluded. ICH is mostly self-limiting and resolves within 12-24 months and usually does not require any treatment. NSAIDs and steroids have been used in symptomatic cases with success. The outcome is generally good with symptoms resolution usually before the age of one year. Relapses are uncommon.

\section{Case Report}

This is a case report of a 74 days of life full term baby born to diabetic mother. Antenatal period was uneventful. At birth, the new born was cyanosed and noted to have systolic murmur. After further assessment, new born was diagnosed with complex cyanotic heart disease (TGA/PDA/ASD/VSD). Child was started on PGE1 infusion at day 3 of life. On day 61 of life, the child was referred to orthopedic team to rule out acute osteomyelitis as noted to have developed swelling over bilateral lower limbs with spiking of temperatures. No family history of similar condition.

On examination, child was active on handling with mild cyanosis. Bilateral lower limbs noted swollen and indurated, more on the right side, extending from hip to foot. It was tender on touch. There was no erythema or areas of collection. Child was not moving his right lower limb. No regional lymphadenopathy noted. Distal circulation was intact. An extensive laboratory work-up for cause of fever was carried out and it was unrewarding. Blood investigation showed raised TWBC of $23\left(10^{3} / \mathrm{uL}\right)$ and ESR $(35 \mathrm{~mm} / \mathrm{hr})$. All other blood investigations were unremarkable. Blood culture showed no growth (Figure 1).

X-ray showed thickening of periosteum involving the diaphysis of bilateral femur, tibia, humerus and radius and ulnar. No osteolytic changes were noted. Metaphysis and epiphysis were sparred. Skeletal survey showed no mandible, ribs or skull involvement. Ultrasound of bilateral lower limbs were done and 
showed symmetrical periosteal reaction likely physiological and heterogenous appearance of bilateral thigh muscles with insinuated fluid with subcutaneous edema. A clinical diagnosis of infantile cortical hyperostosis was made after ruling out other causes. Oral indomethacin for symptom control was suggested, but the parents declined. Child was subjected to conservative treatment.
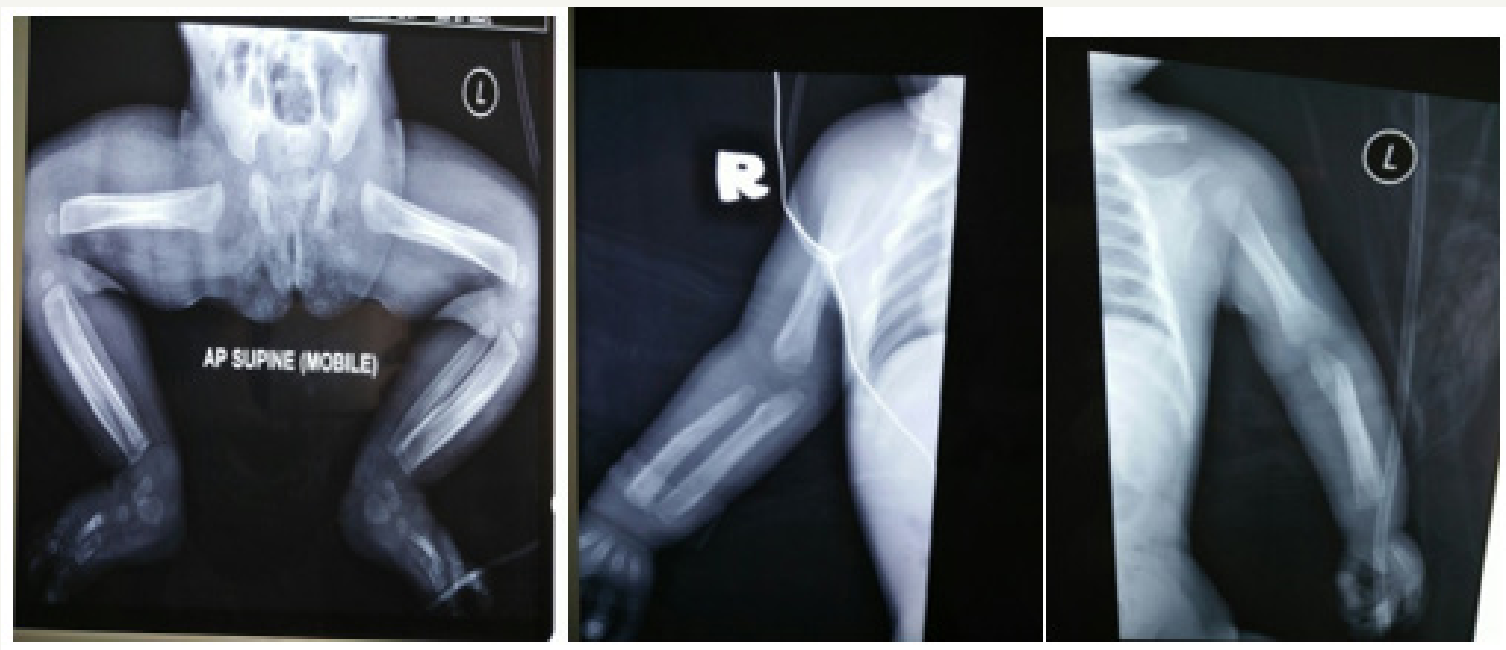

Figure 1: Cortical hyperostosis over long bones.

Child was followed up in orthopedic clinic up to 6 months of life and subsequently defaulted follow up. During the duration of follow up, child did not develop any complications. The symptoms of tenderness and irritability decreased markedly. The legs and arm swellings gradually regressed, and child was moving all limbs freely. The white blood cells, platelets, ALP, and CRP levels were all normalized. However, the periosteal thickening remained present.

\section{Discussion}

Infantile cortical hyperostosis (ICH), also known as Caffey's disease, is a benign self-limiting condition affecting young infants. The initial symptom of the classical ICH is usually irritability, fever and soft tissue swelling affecting one or more bones [1-3]. Fever is usually low grade but occasionally may be spiking reaching up to $39^{\circ}$ Celsius [2]. The swelling is tender, woody like in consistency, non-erythematous and non-suppurative without regional lymphadenopathy which distinguishes from diffuse infection [1]. The pain can be severe and can result in pseudo paralysis. While the soft tissue swellings appear very rapidly, they regress slowly, requiring at times many months to disappear. Diagnosis is usually delayed because its clinical presentation mimics many other clinical conditions such as osteomyelitis, scurvy, hypervitaminosis A, child abuse, bone tumor or even fracture [3-5]. There are no laboratory tests to confirm the diagnosis.

There are two types of ICH been described; the classical mild infantile form and the more severe prenatal form $[3,4]$. The symptoms of the infantile form have been described above and usually presents before the age of 6 months, while the prenatal form presents at birth. The prenatal form is usually associated with other conditions such as polyhydramnios and hydrops fetalis, prematurity and lung disease [3].
Most of the cases of ICH are sporadic, but autosomal dominant and recessive patterns have been reported as well. It is linked with missense mutation in COL1A1, the gene encoding the $\alpha 1$ chain of type I collagen and has raised some doubts whether it is a type of collagen disorder, like osteogenesis imperfecta [6]. The etiology of this condition is still unknown, however several hypotheses have been proposed. Among the proposed causes are infections, immunological defects and genetic abnormalities. Some have suggested that transmission may occur via an infectious agent with a long latency period [1]. Other theories are primary arteriole abnormality of the periosteum causing hypoxic damage leading to periosteal reaction and sub periosteal new bone formation. Other than that, similar lesions have been described in infants who receive exogenous prostaglandins [7-10].

In our case, we believe the cause of the disease is due to the prolonged prostaglandin $\mathrm{E}$ infusion that was started from day 1 of life. Prostaglandin E1 infusion is used for maintaining the patency of ductus arteriosus in ductus dependent congenital heart defects in neonates and is usually administered before corrective heart surgery [8]. The mechanism by which prostaglandin E causes periosteal new bone appears to be related to its physiological role as an inflammatory mediator [11]. Clinical presentation usually appears after more than 40 days of treatment with prostaglandin, although it also has been demonstrated as early as 9 days after the initiation of therapy [12].

In classical ICH, mandible is the most common bone involved, followed by scapula, clavicle, ribs and long bones [3]. Skull and small bones involvement are rare. However, the involvement of mandible is rare in secondary causes of ICH such as due to prostaglandin infusion and hypervitaminosis A $[8,10]$. Our patient did not be involved of mandible. Isolated cases of facial nerve palsy and Erb's 
palsy have also been reported in the literature [2]. Other rare clinical findings are dysphagia, nasal obstruction and proptosis. Pleurisy with small amounts of sterile pleural fluid has been reported in a small number of cases with extensive rib involvement [13]. Our patient did not have any of these uncommon features.

There are no diagnostic laboratory tests for Caffey's disease in general, but the condition is usually associated with high ESR, CRP, alkaline phosphatase, white blood cells, platelet count and immunoglobulin levels [14]. Blood cultures often remains negative. Histologically there is thickening of the periosteum, intense proliferation of sub-periosteal cells and fibrosis of the bone marrow [15]. Radiography is the most valuable diagnostic study. $\mathrm{X}$ ray features show layers of periosteal new bone formation, with cortical thickening sparing the metaphysis and epiphysis [1]. Softtissue swelling is evident as well. Though the radiographic changes are very prominent, they are not pathognomonic. There are no radiographic evidence of destruction or interruption of cortex.

In view ICH is a very rare disease, other conditions like acute osteomyelitis, chronic hypervitaminosis A, bone tumour, scurvy and child abuse need to be excluded. Excessive intake of vitamin A may produce periosteal proliferation like those observed in patients with ICH. Characteristically this condition occurs after one year of age in contrast to ICH which occurs within 6 months of life. Metatarsal involvement is very common and characteristic feature of hypervitaminosis A [3]. Non-accidental injury (NAI) or child abuse is another important differential diagnosis to be kept in mind. They present with extensive periosteal reaction over multiple bones. Periosteal reaction is usually seen in fracture repair but can occur in the absence of fracture because of gripping or twisting force alone. The periosteal reaction is always confined to the diaphysis in ICH but may extend into metaphysis and epiphysis in NAI [5].

ICH is mostly self-limiting and resolves within $12-24$ months and usually does not require any treatment. Anti-inflammatory drugs such as NSAIDS (indomethacin and naproxen) and steroids has been used in symptomatic cases with success [2]. The rationale for using NSAIDs is based on their prostaglandin synthetase inhibiting action. The clinical course is variable and unpredictable but usually the acute symptoms resolve over few months. The outcome is generally good with symptoms resolution usually before the age of one year. Synostosis can occur when paired bones such as tibia and fibula or radius and ulnar is involved causing impairment in rotation [3]. When adjacent ribs are involved, it can lead to thoracic scoliosis and respiratory compromise [13]. Relapses are uncommon.

\section{Conclusion}

The aim of this report is to highlight the rare complication that may arise from prolong use of prostaglandin in new-borns with congenital heart disease. High index of suspicion is essential to make the diagnosis. Treatment is usually conservative. The course of the illness is generally benign and recovers completely in many cases without treatment by 1 year.

\section{References}

1. Bianconi M, Ferraro L, Traina GC, Zanoli G, Antonelli T, et al. (2003) Pharmacokinetics and efficacy of ropivacaine continuous wound instillation after joint replacement surgery. Br J Anaesth 91(6): 830-835.

2. Kerr DR, Kohan L (2008) Local infiltration analgesia: a technique for the control of acute postoperative pain following knee and hip surgery: a case study of 325 patients. Acta Orthop 79(2): 174-183.

3. Eeden van den YNT, De Turck BJG, Eeden van den FMC (2017) 24 hours stay after hip replacement. Acta Orthopaedica 88(1): 24-28.

4. Glassou EN, Pedersen AB, Hansen TB (2014) Risk of re-admission, reoperation, and mortality within 90 days of total hip and knee arthroplasty in fast-track departments in Denmark from 2005 to 2011. Acta Orthop 85(5): 493-500.

5. Hartog den YM, Mathijssen NM, Vehmeijer SB (2013) Reduced length of hospital stay after the introduction of a rapid recovery protocol for primary THA procedures. Acta Orthop 84(5): 444-447.

6. Husted H, Hansen HC, Holm G, Bach-Dal C, Rud K, et al. (2010) What determines length of stay after total hip and knee arthroplasty? A nationwide study in Denmark. Arch Orthop Trauma Surg 130(2): 263268.

7. Husted H, Jensen CM, Solgaard S, Kehlet H (2012) Reduced length of stay following hip and knee arthroplasty in Denmark 2000-2009: from research to implementation. Arch Orthop Trauma Surg 132(1): 101-104.

8. Andersen KV, Pfeiffer-Jensen M, Haraldsted V, Søballe K (2007) Reduced hospital stay and narcotic consumption, and improved mobilization with local and intraarticular infiltration after hip arthroplasty: a randomized clinical trial of an intraarticular technique versus epidural infusion in 80 patients. Acta Orthop 78(2): 180-186.

9. Affas F, Nygårds EB, Stiller CO, Wretenberg P, Olofsson C (2011) Pain control after total knee arthroplasty: a randomized trial comparing local infiltration anesthesia and continuous femoral block. Acta Orthop 82(4): 441-447.

10. Andersen J, Poulsen T, Krogh B, Nielsen T (2007) Postoperative analgesia in total hip arthroplasty: a randomized, double-blind, placebo-controlled study on peroperative and postoperative ropivacaine, ketorolac and adrenaline wound infiltration. Acta Orthop 78(2): 187-192.

11. Niemeläinen M, Kalliovalkama J, Aho AJ, Moilanen T, Eskelinen A (2014) Single periarticular local infiltration analgesia reduces opiate consumption until 48 hours after total knee arthroplasty. A randomized placebo-controlled trial involving 56 patients. Acta Orthop 85(6): 614619.

12. Dobie I, Bennett D, Spence DJ, Murray JM, Beverland DE (2012) Periarticular local anesthesia does not improve pain or mobility after THA. Clin Orthop Relat Res 470(7): 1958-1965.

13. den Hartog YM, Mathijssen NM, van Dasselaar NT, Langendijk PN, Vehmeijer SB (2015) No effect of the infiltration of local anaesthetic for total hip arthroplasty using an anterior approach: a randomised placebo-controlled trial. Bone Joint J 97-B(6): 734-740.

14. Hofstad JK, Winther SB, Rian T, Foss OA, Husby OS, et al. (2015) Perioperative local infiltration anesthesia with ropivacaine has no effect on postoperative pain after total hip arthroplasty. Acta Orthop 86(6): 654-658.

15. Lunn TH, Husted H, Solgaard S, Kristensen BB, Otte KS, et al. (2011) Intraoperative local infiltration analgesia for early analgesia after total hip arthroplasty: a randomized, double-blind, placebo-controlled trial. Reg Anesth Pain Med 36(5): 424-429.

16. Solovyova O, Lewis CG, Abrams JH, Benson GJ, Joyce ME, et al. (2013) Local infiltration analgesia followed by continuous infusion of local anesthetic solution for total hip arthroplasty: a prospective, randomized, double-blind, placebo-controlled study. J Bone Joint Surg Am 95(21): 1935-1941. 
17. Zoric L, Cuvillon P, Alonso S, Demattei C, Vialles N, et al. (2014) Singleshot intraoperative local anaesthetic infiltration does not reduce morphine consumption after total hip arthroplasty: a double-blinded placebo-controlled randomized study. Br J Anaesth 112(4): 722-728.

18. Andersen LØ, Husted H, Otte KS, Kristensen BB, Kehlet H (2008) Highvolume infiltration analgesia in total knee arthroplasty: a randomized double-blind, placebo-controlled trial. Acta Anaesthesiol Scand 52(10): 1331-1335.

19. Andersen LØ, Larsen GL, Kristensen BB, Husted H, Otte KS, et al. (2010) Analgesic efficacy of local anaesthetic wound administration in knee arthroplasty: volume vs concentration. Anaesthesia 65(10): 984-990.

20. Husted H, Lunn TH, Troelsen A, Larsen GL, Kristensen BB, et al. (2011) Why still in hospital after fast-track hip and knee arthroplasty? Acta Orthop 82(6): 679-684.

21. Jorgensen CC, Kehlet H, Lundbeck Foundation Centre for Fast-track H and Knee replacement collaborative G (2013) Role of patient chararteristics for fast-track hip and knee arthroplasty. Br J Anaesth 110(6): 972-980.

22. Eeden van den FMC, Eeden van den YNT (2018) Local infiltration anesthesia in total knee and total hip arthroplasty: A brief review. J Anest \& Inten Care Med 5(3): 1-3.

23. Andersen LØ, Otte KS, Husted H, Larsen LG, Kristensen B, et al. (2011) High-volume infiltration analgesia in bilateral hip arthroplasty A randomized, double-blind placebo-controlled trial. Acta Orthop 82(4): 423-426.

24. Andersen KV, Nikolajsen L, Daugaard H, Andersen NT, Haraldsted V, et al. (2015) Local infiltration analgesia is not improved by postoperative intra-articular bolus injections for pain after total hip arthroplasty. A randomized, double-blind, placebo-controlled study with 80 patients. Acta Orthop 86(6): 647-653.
25. Kuchálik J, Granath B, Ljunggren A, Magnuson A, Lundin A, et al. (2013) Postoperative pain relief after total hip arthroplasty: a randomized, double-blind comparison between intrathecal morphine and local infiltration analgesia. Br J Anaesth 111(5): 793-799.

26. Murphy TP, Byrne DP, Curtin P, Baker JF, Mulhall KJ (2012) Can a periarticular levobupivacaine injection reduce postoperative opiate consumption during primary hip arthroplasty? Clin Orthop Relat Res 470(4): 1151-1157.

27. Gupta T, Garg N, Gupta M (2014) Local infiltration analgesia following total hip replacement: a review of current literature. Chinese Journal of Traumatology 17(5): 293-297.

28. Liu W, Cong R, Li X, Wu Y, Wu H (2011) Reduced opioid consumption and improved early rehabilitation with local and intraarticular cocktail analgesic injection in total hip arthroplasty: a randomized controlled clinical trial. Pain Med 12(3): 387-393.

29. Johnson RL, Kopp SL, Burkle CM, Duncan CM, Jacob AK, et al. (2016) Neuraxial vs general anaesthesia for total hip and total knee arthroplasty. a systematic review of comparative-effectiveness research. Br J Anaesth 116(2): 163-176.

30. Bush CA, Whitehouse MR, Shore BJ, MacDonald SJ, McCalden RW, et al. (2010) The efficacy of periarticular multimodal drug infiltration in total hip arthroplasty. Clin Orthop Relat Res 468(8): 2152-2159.

31. Scott CE, Streit J, Biant LC, Breusch SJ (2012) Periarticular infiltration in total hip replacement: effect on heterotopic ossification, analgesic requirements and outcome. Arch Orthop Trauma Surg 132(5): 703-709.
Creative Commons Attribution 4.0 International License

For possible submissions Click Here

\section{Submit Article}

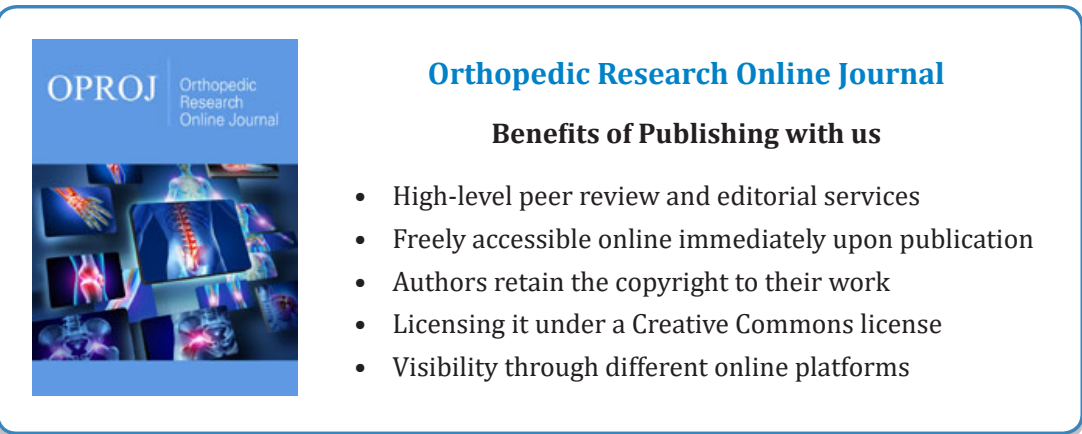

